\title{
Crustal Deformation Across and beyond Central Europe and Its Impact on Land Boundaries
}

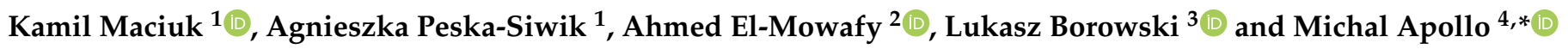 \\ 1 Department of Integrated Geodesy and Cartography, AGH University of Science and Technology, \\ 30-059 Krakow, Poland; maciuk@agh.edu.pl (K.M.); peska@agh.edu.pl (A.P.-S.) \\ 2 School of Earth and Planetary Sciences, Curtin University, Perth 6102, Australia; A.El-Mowafy@curtin.edu.au \\ 3 Department of Geotechnical Engineering, Faculty of Civil Engineering and Architecture, Lublin University of \\ Technology, 20-618 Lublin, Poland; 1.borowski@pollub.pl \\ 4 Department of Tourism and Regional Studies, Institute of Geography, Pedagogical University of Cracow, \\ 30-084 Kraków, Poland \\ * Correspondence: michal.apollo@up.krakow.pl
}

check for updates

Citation: Maciuk, K.; Peska-Siwik,

A.; El-Mowafy, A.; Borowski, L.; Apollo, M. Crustal Deformation Across and beyond Central Europe and Its Impact on Land Boundaries. Resources 2021, 10, 15. https:// doi.org/10.3390/resources10020015

Academic Editor: Volker Beckmann

Received: 7 January 2021

Accepted: 10 February 2021

Published: 12 February 2021

Publisher's Note: MDPI stays neutral with regard to jurisdictional claims in published maps and institutional affiliations.

Copyright: (c) 2021 by the authors. Licensee MDPI, Basel, Switzerland. This article is an open access article distributed under the terms and conditions of the Creative Commons Attribution (CC BY) license (https:/ / creativecommons.org/licenses/by/ $4.0 /)$.
Abstract: Land is a critical and limited natural resource. The Land Administration System (LAS) has been developed to resolve and adjudicate over any disputes that might arise concerning the rights and boundaries of land. Land registration and cadastre are types of land recording that need to be established. To secure the property rights, we must be sure of accuracy of the boundary points determining the size of the property. However, in addition to typical factors considered when determining the boundary point positions, such as accuracy of geodetic networks and measurement errors, the global and local crustal deformation, resulting, e.g., from the movement of tectonic plates, should be considered. In this work, the focus is on the movement of points inside the European plate due to tectonic movement, without taking into account local events caused by erosion, landslides, etc. The study area is Europe, and particular attention was paid to Poland, which is located in the centre of the European continent and does not have significant anomalous sub-areas, making it an authoritative research object. In this study, we analysed the velocity of point displacements and the boundary deformation, using GPS observations. For this reason, we used both global (IGS) and regional (ETRF) reference frames, to show differences in point velocities for the studied areas. Overall, for the needs of the real estate cadastre in Poland, information about parcel boundary points must be obtained with an accuracy better than $0.30 \mathrm{~m}$. Within 25 years, the border mark may be shifted by $0.13 \mathrm{~m}$ due to tectonic plate movement, which is within the required accuracy. Pursuant to the current legal regulations, the measurements of the boundary points can be performed with any method, ensuring the required accuracy $(0.30 \mathrm{~m})$. The most commonly used are direct measurements (GNSS and tacheometry) and photogrammetric measurements. It is recommended that periodic verifications and update of the cadastre data in Poland be carried out at least once every 15 years. In the case of such relatively frequent verification and possible modernisation of data, the potential impact of tectonic plate movement on the relative boundary point displacement can be ignored, particularly in the short term. However, for a long time period it has an influence. We suggest "relatively frequent" cadastral boundary verification to be able to ignore such influence.

Keywords: boundaries; deformation; GNSS; parcels; tectonic plate movement

\section{Introduction}

The real estate cadastre is a public register, the purpose of which is to protect one of the most valuable rights, the property rights [1]. The extent of the property is determined by the location of the boundary points $[2,3]$, and, therefore, these locations directly affects the area of the property, which in turn affects the value of the property [4,5]. Through it, boundary points are essential for the Land Administration System (LAS). It has to be noted that the cadastre remains a most important tool because it is capable of supporting all 
functions in the land management paradigm (noting that the cadastre is more correctly a number of tools within one conceptual framework). Indeed, any LAS designed to support sustainable development will make the cadastre its most important tool. The global idea of LAS is to determine the infrastructures for the implementation of land policies and land management strategies in support of sustainable development [6-8]. For this reason, when determining the location of the border point, it is necessary to be as accurate as possible and to take into account all possible variables influencing the obtained coordinates of the point [9]. The variables that affect the accuracy of the location of the border point are primarily errors in the geodetic control points' positions used as a reference and the accuracy of the used method. This has to include the impact of, among others, errors in the geodetic control points' positions used as a reference and the accuracy of the method used [10-13]. Another important aspect is to evaluate whether the accuracy of determining the location of boundary points is influenced by global and local crustal deformations due to plate tectonics.

Plate tectonics is the large-scale motion of nine large plates and many minor plates of the Earth's lithosphere, which is the rigid crust and upper mantle (outermost shell) of the Earth. The lithosphere is cooler and more rigid and rides on the hotter fluid-like layer of the asthenosphere. The driving forces for tectonic plates motion are categorised into those related to mantle dynamics, gravity and Earth's rotation. The friction between the mantle convection currents and gravity that exerts a downward pull on plates in subduction zones were considered as two main reasons for the plate motion due to mantledynamic forces. However, other theories, such as plume and surge tectonics, tried to modify earlier theories based on, e.g., 3D computer modelling [14]. Currently, gravityrelated forces are considered as the main reason for plate motions and are divided into three sub-categories: the gravitational sliding away from a spreading ridge [15], slab pull [16] and the gravitational sliding away from mantle doming [17]. Other forces that have impacts on plate motions are the tidal effects due to the Sun and the Moon gravity, the polar motion, precision and nutation, the Coriolis and centrifugal forces. They are generally considered as the Earth rotation-related forces. The relative significance of these forces and their possible relationship is still under investigation. As the surveying points and boundary points are fixed on the tectonic plates, their absolute positions change over time.

The main aim of this study was to check the deformation of boundary points and answer the question of whether movement on the relative boundary point displacement is important for estimating the precise location of the cadastral parcel boundary points. This deformation was calculated based on positions and velocities of the EUREF Permanent GNSS Network (EPN) stations, in the global International GNSS Service reference frame (IGS14) and the local European Terrestrial Reference Frame (ETRF2014). These positions and velocities were derived from a multi-year combination of the EPN daily combined Station-Independent-Exchange Format (SINEX) files. The study was conducted in Europe, with special attention to Poland. Since it is located in the centre of the European continent and it does not have significant anomalous sub-areas, Poland is a reliable case study and thus this research has a universal character.

\section{Background}

The cadastral data are usually referenced to an ellipsoid, and the impact of vertical motions (heights) needs to be considered. Changes of heights, using a geoid as a reference surface, may be caused by: (i) locally by mining [18]; (ii) regionally by Earth crust movements [19]; and (iii) globally by the uplift of the sea level [20]. The last factor has the longest research history, for example, about 250 years for the area of the Baltic Sea [21]. The average trend of the Baltic Sea absolute uplift is about $+1.3 \mathrm{~mm} /$ year, which is slightly below the global mean for the same period [21]. Relative to land, the value of movement in the southern part of this area is higher, whereas, in the northern part, the sea level is decreasing (down to $-9 \mathrm{~mm} /$ year). This is due to the post-glacial rebound of the Scandinavian Peninsula. The absolute movement is calculated with the assumption of the Earth's 
crust low-frequency movement, which permits treating changes of the absolute sea level as a difference between two datasets, i.e., changes of the sea level recorded by tide gauges and the vertical movement of Earth's crust taken from GNSS permanent stations [22]. Satellite altimetry observations provide a little difference in the absolute value of the Baltic sea of $+4 \mathrm{~mm} /$ year compared to a global uplift of $+3.3 \mathrm{~mm} /$ year [23].

The cadastral data need to be defined in a well-defined coordinated frame, e.g., in a Terrestrial Reference Frame (TRF), which is based on a set of points with coordinates determined in a specific system [24], i.e., a Terrestrial Reference System (TRS). A Terrestrial Reference System (TRS) is a spatial reference system close to Earth's surface and co-rotating with its diurnal motion in space. Its origin is the centre of the Earth's mass (geocenter), the orientation is equatorial, with the pole in the Z-axis direction, and the scale is close to an SI metre [25]. Due to the geophysical effects (tidal and tectonic deformations), points on the solid surface of the Earth have small variations in time. These have been considered by using an International TRS (ITRS). The International Earth Rotation and Reference System Service (IERS) maintains, defines, promotes and realises the ITRS as defined by the International Union of Geodesy and Geophysics (IUGG) Resolution No. 2 adopted in Vienna, 1991 [26]. For details of the ITRS description and definition, the reader can refer to [27]. The International Terrestrial Reference Frame (ITRF) is a practical realisation of the ITRS. ITRF is regularly updated both by new data (e.g., reprocessing) and new strategies applied by analysis centres [28]. Twelve ITRF realisations have been published to date, starting with ITRF88 up to the latest, currently operational ITRF2014 [29]. WGS84 (World Geodetic System 1984) has been connected with ITRS since 1994 [30] and shows consistency at about $10 \mathrm{~cm}$ level. ITRF realisation is based on four techniques: GNSS (Global Navigation Satellite System), SLR (Satellite Laser Ranging), VLBI (Very Long Baseline Interferometry) and DORIS (Doppler Orbitography and Radiopositioning Integrated by Satellite) [31].

ITRF is currently the most accurate global reference frame, defined by the above techniques, although none of them can provide alone the defining parameters of a full reference frame. The ITRF origin is defined by SLR data, the scale is determined by SLR and VLBI and the ITRF orientation is maintained by successive ITRF releases [32]. Each ITRF combination highly depends on the availability of sites where at least two observation techniques (GNSS, VLBI, SLR and DORIS) are operated and local surveys between instrument measuring points are available. These local surveys are usually conducted either by a precise GNSS technique or by terrestrial instruments (precise total stations, levels). Connections between the positioning reference points are provided by agencies, where ITRF sites are operating, using least square adjustments of local surveys [29]. Usually, a current ITRF $y y$ is used, where " $y y$ " denotes the year of the ITRF realisation. In some areas, fiducial station coordinates might be available in a local system (usually of a continent-size), e.g., ETRS (European Terrestrial Reference System) and its practical realisation ETRF $_{y y}$ (European Terrestrial Reference Frame) for Europe.

In this paper, we investigate the effect of local tectonic movements on the location (defined by coordinates) of the parcel's boundary points. To determine the above-mentioned impacts, EPN (European Permanent GNSS Network) reference stations' velocities based on multi-year observations were used. From these velocities, practical movements were determined that may affect the change of the location of boundary points, which should be determined with the highest possible accuracy. For this reason, it is important to know whether it is necessary to take into account the movements of the tectonic plates when determining the location of boundary points.

Conversion between coordinates from different realisations, e.g., from $\left(X_{1}, Y_{1}, Z_{1}\right)$ to $(X, Y, Z)$, could be done using a seven-parameter similarity transformation expressed as $[33,34]$ :

$$
\left[\begin{array}{l}
X \\
Y \\
Z
\end{array}\right]=\left[\begin{array}{l}
X_{1} \\
Y_{1} \\
Z_{1}
\end{array}\right]+\left[\begin{array}{l}
T_{1} \\
T_{2} \\
T_{3}
\end{array}\right]+\left[\begin{array}{ccc}
k & R_{z} & -R_{y} \\
-R_{z} & k & R_{x} \\
R_{y} & -R_{x} & k
\end{array}\right]\left[\begin{array}{l}
X_{1} \\
Y_{1} \\
Z_{1}
\end{array}\right]
$$


where $T_{1}, T_{2}, T_{3}$ are translation parameters, $R_{x}, R_{y}, R_{z}$ are rotation parameters and $k$ is a scale factor. According to the ITRF definitions and realisations, it is a kinematic (dynamic) frame, where points on the Earth's crust exhibit position changes caused by local and global tectonic movements. As a result of that, each ITRF solution contains coordinates and velocities of its fiducial stations at a specific epoch expressed as [35]:

$$
\boldsymbol{X}^{i}\left(t_{c}\right)=\boldsymbol{X}^{i}\left(t_{0}\right)+\dot{X}^{i}\left(t_{c}-t_{0}\right)
$$

where $X^{i}\left(t_{c}\right)$ is the $[X, Y, Z]$ Cartesian coordinate vector of a fiducial station $I$ at the epoch $t_{c}, X^{i}\left(t_{0}\right)$ is its known coordinate vector at the reference epoch $t_{0}$ and $\dot{X}$ is the corresponding velocity vector. To estimate these velocities, an absolute tectonic plate motion model was determined based on the observations in the ITRF2014 (Figure 1), using high-quality observations from 206 core sites [36,37].
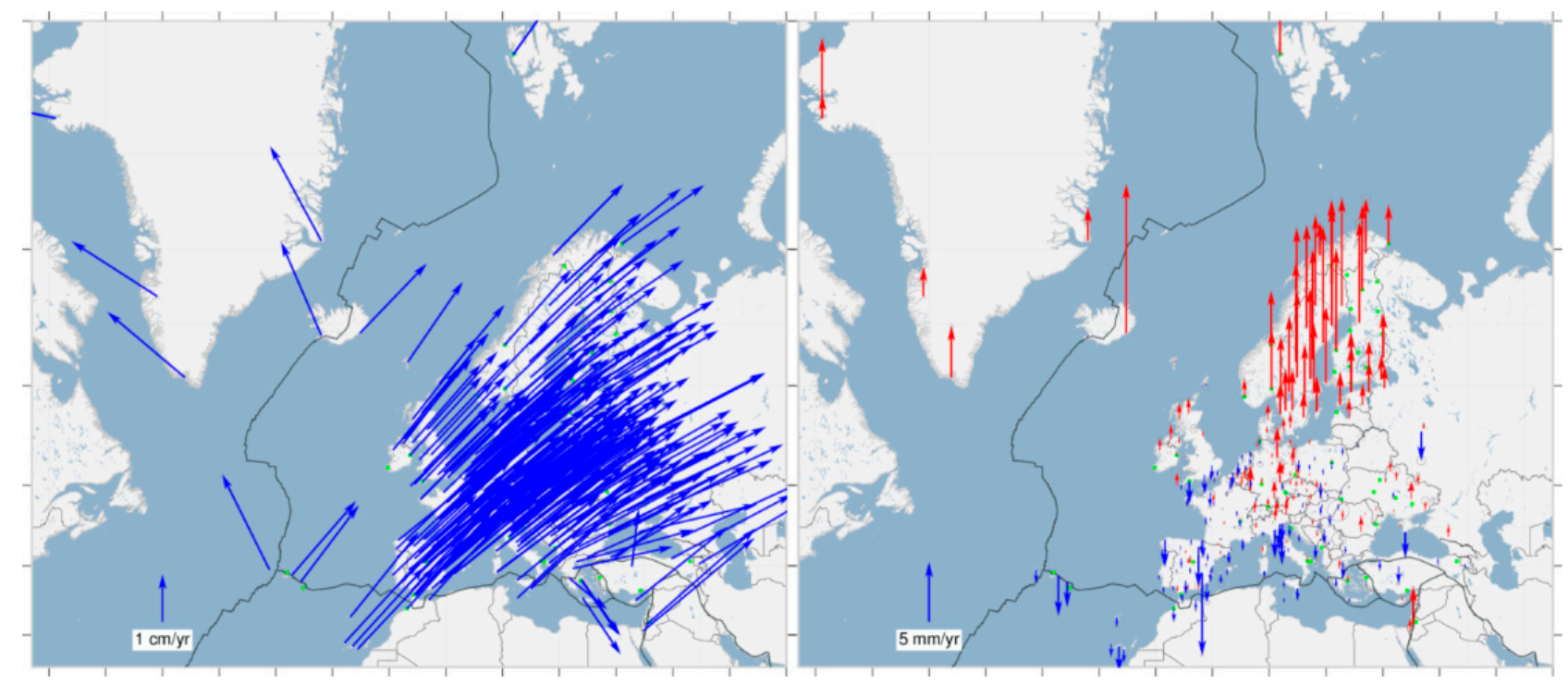

Figure 1. ITRF2014 horizontal velocity field (left) and vertical velocity (right), derived from the latest EPN cumulative solution. The subsidence is indicated by blue arrows and the uplift is indicated by red arrows (source: [38]).

\section{Methods}

The International Association of Geodesy (IAG) Sub-commission for the European Reference Frame (EUREF) created Resolution 1 at the 1990 meeting in Florence, states: "The IAG Subcommission for the European Reference Frame recommends that the system to be adopted by EUREF will be coincident with the ITRS at the epoch 1989.0 and fixed to the stable part of the Eurasian Plate and will be known as European Terrestrial Reference System 89 (ETRS89)" [39]. According to this definition, ETRS89 is relative to the ITRS through similarity transformation. Based on the current realisation of $\mathrm{ITRF}_{y y}$, a corresponding reference frame in ETRS89 called ETRF $y y$ is established based on core sites defined in the ITRF and located in Europe. Figure 2 shows the calculation framework between current realisations of ITRF and ERTS89 at an input epoch $t_{0}$ to an output epoch $t_{c}$.

In this work, an investigation of the deformation of boundary points is carried out. This deformation is calculated based on positions and velocities of EPN stations, in the global International GNSS Service reference frame (IGS14) and the local (ETRF2014) reference frames, derived from a multi-year combination of the EPN daily combined SINEX files. This multi-year solution is used for the realisation of the regional densification of the $\mathrm{ITRF}_{y y} / \mathrm{IGS}_{y y}$ between two releases and for the maintenance of the ETRS89. The multi-year combination comprises EPN-repro2 daily SINEX files from GPSweek 834 to GPSweek 1772 and routine daily EPN combined SINEX files from GPSweek 1772 to the most recent 
solutions. The multi-year solution is updated every 15 weeks in order to provide up-to-date coordinates and velocities [41].

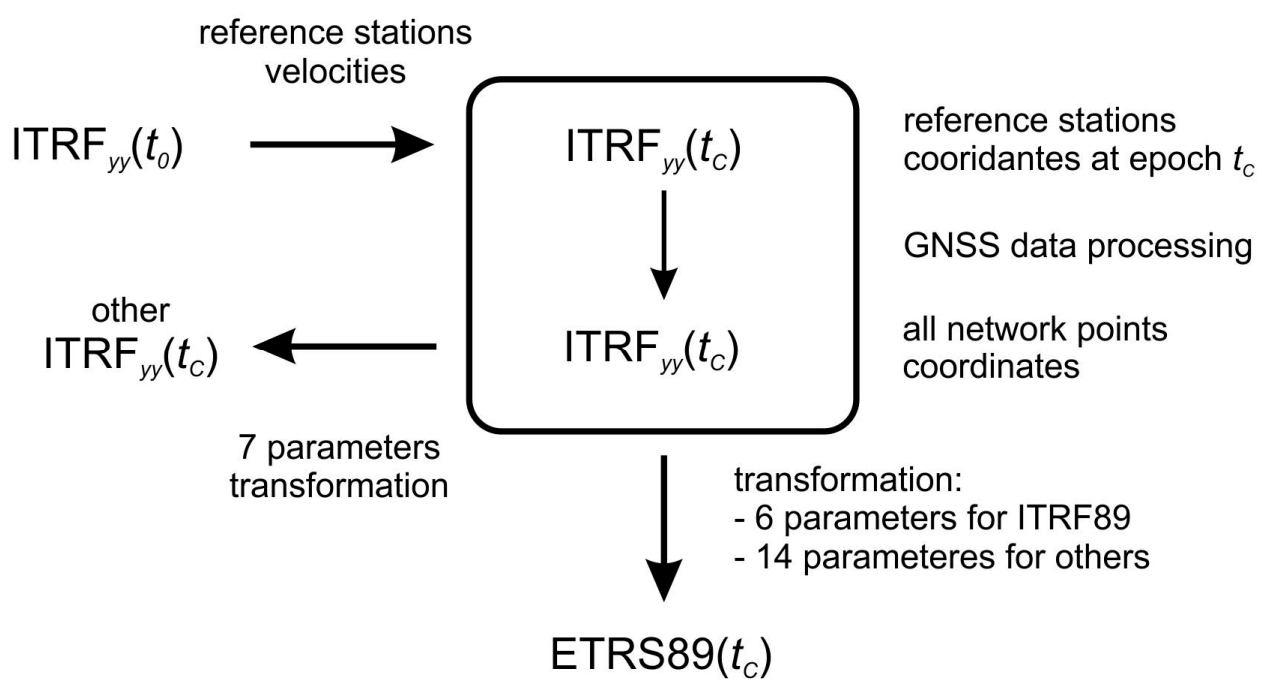

Figure 2. ITRF yy $_{y}$ and ETRS89 calculation schema (own study based on $[39,40]$ ).

There are two possibilities of transformation between station coordinates from $\mathrm{ITRF}_{y y}$ to $\mathrm{ETRF}_{y y}$ at an epoch $t_{c}[39]$ :

1. GNSS solutions of the selected points are processed in ITRF $F_{y y}$ (e.g., ITRF2014) and transformed to the target ETRS89 reference frame, the ETRF $y$ (e.g., ETRF2014), corresponding to the ITRF ${ }_{y y}$. Calculations are made by a simple formula:

$$
X_{y y}^{E}\left(t_{c}\right)=X_{y y}^{I}\left(t_{c}\right)+T_{Y Y}+\left[\begin{array}{ccc}
0 & -\dot{R} 3_{y y} & \dot{R} 2_{y y} \\
\dot{R} 3_{y y} & 0 & -\dot{R} 1_{y y} \\
-\dot{R} 2_{y y} & \dot{R} 1_{y y} & 0
\end{array}\right] \times X_{y y}^{I}\left(t_{c}\right) \cdot\left(t_{c}-1989.0\right)
$$

and for the velocities:

$$
\dot{X}_{y y}^{E}\left(t_{c}\right)=\dot{X_{y y}^{I}}+\left[\begin{array}{ccc}
0 & -\dot{R} 3_{y y} & \dot{R} 2_{y y} \\
\dot{R} 3_{y y} & 0 & -\dot{R} 1_{y y} \\
-\dot{R} 2_{y y} & \dot{R} 1_{y y} & 0
\end{array}\right] \times X_{y y}^{I}
$$

where $X$ and $\dot{X}$ refer to station positions and velocities, respectively, and the indexes $I$ and $E$ represent the systems ITRS and ETRS89, respectively. The rotation rate parameters $\dot{R} 1_{y y}, \dot{R} 1_{y y}, \dot{R} 1_{y y}$ are expressed in the ITRF $F_{y y}$ and translation vector $T_{y y}$ is the global offset between ITRF versions. The rotation and translation values are available in the literature [39].

2. GNSS solutions are processed in $\mathrm{ITRF}_{y y}$ (e.g., ITRF2008) and the target ETRS89 reference frame is $\operatorname{ETRF}_{x x}$ (e.g., ETRF2000), which do not correspond to the ITRF $F_{y y}$. Calculations are made in two steps: transforming coordinates at the epoch $t_{0}$ from $\mathrm{ITRF}_{y y}$ into ITRF $x x$ using Equation (1) and from epoch $t_{0}$ to epoch $t_{c}$. The second step is similar to Point 1, by using Equations (3) and (4).

Because $\mathrm{ETRF}_{y y}$ is realised and maintained by stations located on the European territory, the velocities are much smaller than those in the global ITRF ${ }_{y y}$. Figure 3 shows the ETRF2014 horizontal velocity field (left) and vertical velocity (right) derived from the latest EPN cumulative solution. Note that the scale of horizontal displacements in Figure 1 (left) and Figure 3 (left) are different. Most of the European territory has $<1 \mathrm{~mm} /$ year horizontal and vertical velocities. In the case of horizontal velocities, only a couple of 
stations, located in Turkey and the Apennine and Balkan Peninsulas, experience velocities significantly larger than $1 \mathrm{~mm}$ /year. As can be observed, the vector directions have a stochastic character. Therefore, in addition to global and local tectonic plate movements, the error in velocity determination must be taken into account for these stations. In the case of vertical displacement, for both ITRF2014 and ETRF2014 the velocity magnitudes are at the 1-2 mm/year level, except for the Fennoscandia region (the region including the Scandinavian Peninsula, Finland, Karelia and the Kola Peninsula) and Icelandic territory, which are uplifted against the rest of the European territory $[42,43]$.
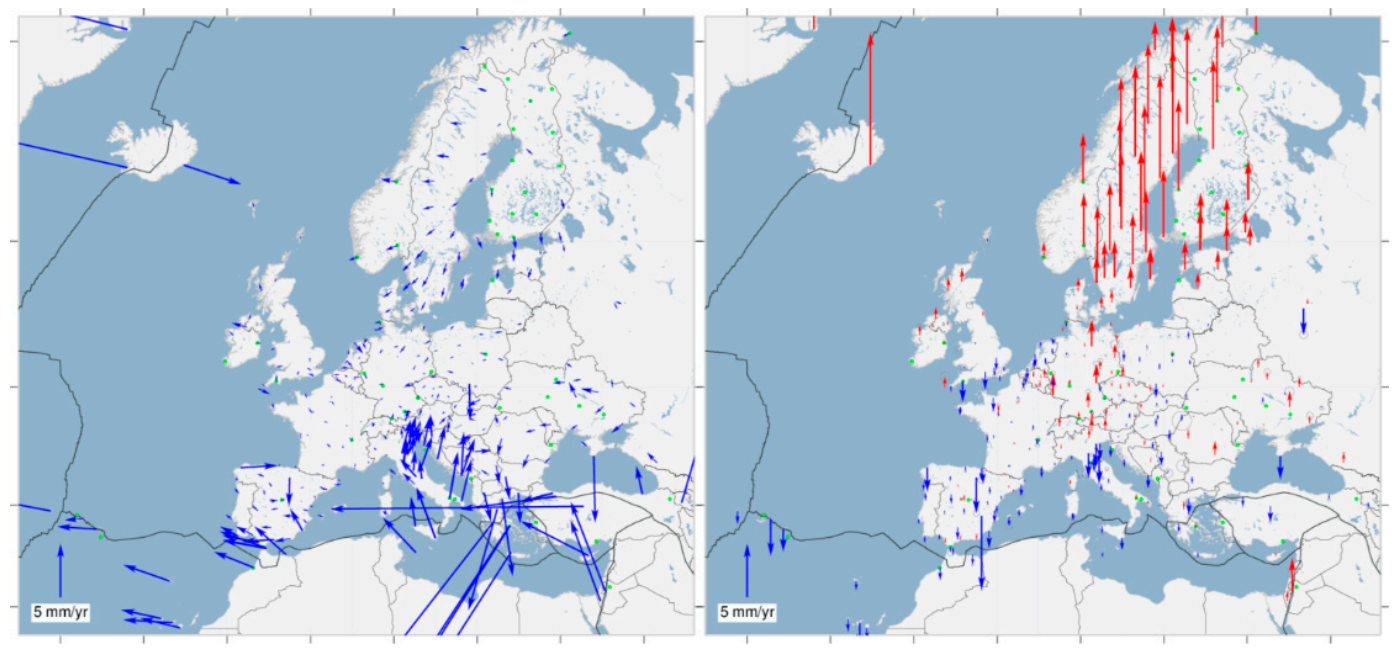

Figure 3. ETRF2014 horizontal velocity field (left) and vertical velocity (right), derived from the latest EPN cumulative solution. The subsidence is indicated in blue arrows, and the uplift in red arrows. The velocities are expressed with respect to the Eurasian plate. The green dots represent sites with less than three years of observations (source: [38]).

\section{Results}

Land and buildings are the basic objects of cadastral parcels. Determining the location and shape of the cadastral plot is therefore limited to determining locations of its boundary points. Since point locations are defined by their coordinates, the cadastre objects spatial accuracy will be directly related to the accuracy of determining these boundary points' coordinates. These coordinates can be obtained by

- $\quad$ Direct field measurements

- Photogrammetric measurements

- Carthometric measurements

The most accurate method is positioning using direct field measurements, such as by using precise GNSS measurements and angular-linear measurements of total stations $[44,45]$. This kind of the measurements is used in various engineering areas (e.g., [46-48]). The accuracy of the photogrammetric measurements depends on the used scale and accuracy of the control points and type of land cover, and, in general, they are used for large areas. Information on the boundary point location can also be obtained from geodetic carthometric measurements (vectorisation and digitisation); however, these methods are not considered accurate enough. The low quality of their data is due to the fact that such data are obtained in a secondary process, which involves processing existing information into another form. In each of the indicated methods, the measurements are made with reference to geodetic control points with known coordinates. In the case of measurements made in small areas, it can be assumed that both the control points and boundary marks are located on the same tectonic plate and move in the same direction. In a local context, the shift of boundary characters using geodetic control points with specified coordinates that are not updated would be impossible to determine. 
Based on the multi-year observations from 249 permanent reference stations covering the European continent, their positions and velocities are determined and made publicly available in both global (IGS14) and local (ETRF2000 or ETRF2014) reference frames at epoch 2010.0 [41]. Based on these products, the tectonic plate movements and velocities are computed, and contour values of the velocities are illustrated in Figures 4 and 5. Since the point coordinates of parcel's boundaries are shown in plane coordinates ( $\mathrm{X}$ and $\mathrm{Y})$, only these are analysed.
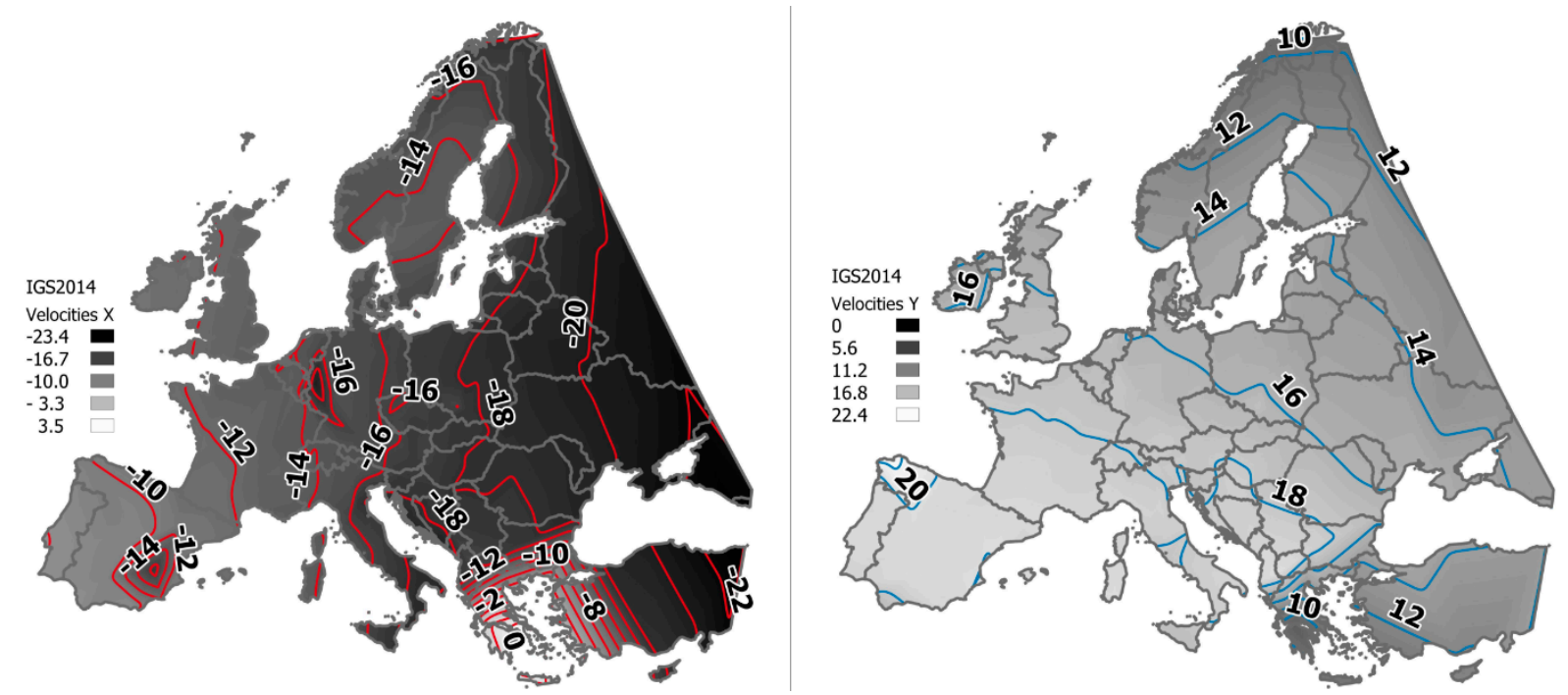

Figure 4. European plate velocities (mm/year) in IGS14: X component (left); and Y component (right) (own study based on [41]).
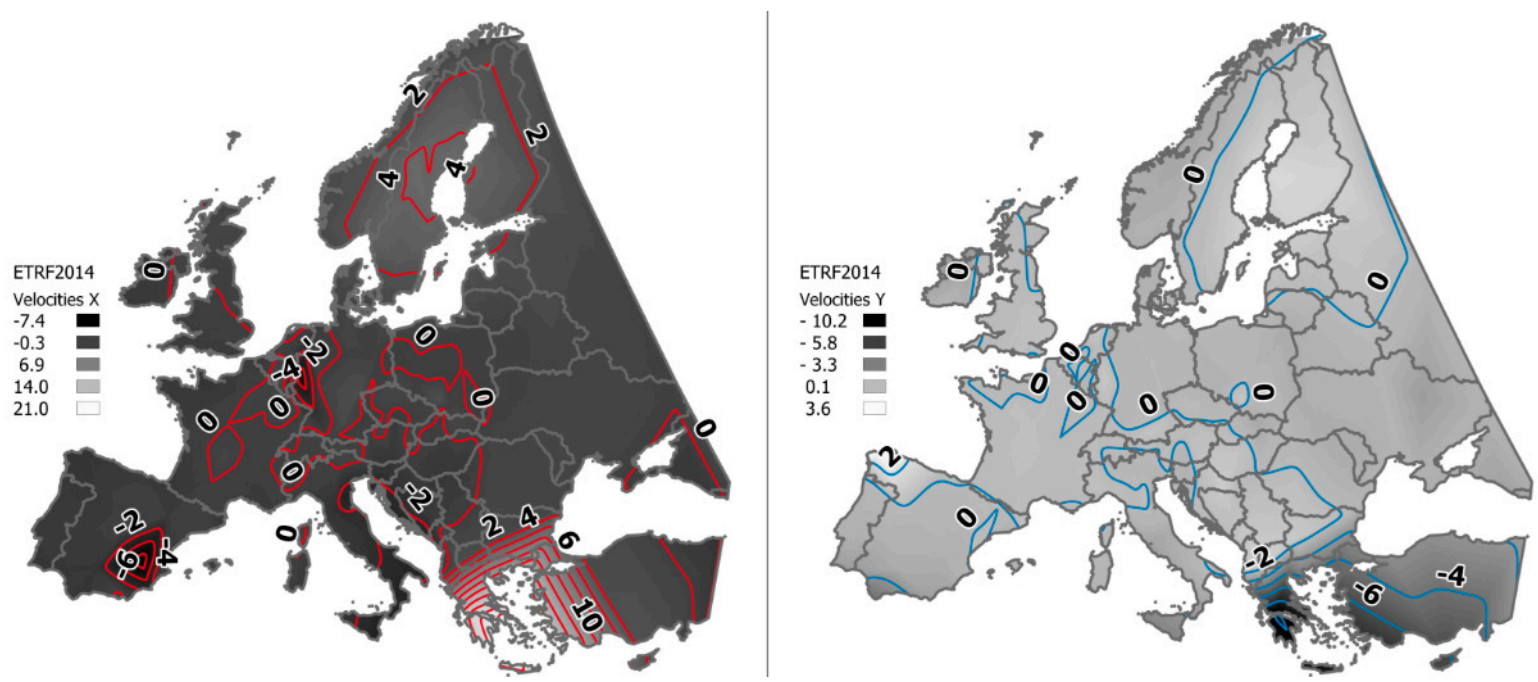

Figure 5. European plate velocities (mm/year) differences from the mean in ETRF2014: X component (left); and Y component (right) (own study based on [41]).

The same scale is used in Figures 4 and 5 for better interpretation that shows the magnitudes of velocities in the global (IGS14) and local (ETRF2014) reference frames.

Figure 4 shows velocities in the $X$ and $Y$ direction in the global IGS14. Resultant of these two components is a very clear northeast direction 2D movement with a mean amplitude of 22-25 mm/year for the centre of Europe (computed as the square root of the sum of the squares of movements in $X$ and $Y$ directions). The Balkan and Turkey area is an exception (Peloponnese, especially). Three stations (PAT0, DYNG and TUC2) indicate no X change. Their differences are better shown in the ETRF2014 frame (Figure 5) by removing 
the mean shift between the two frames. Very low amplitudes of $Y$ is shown for almost the whole European plate. The changes in $X$ are more diverse. At least some of them have an anthropodermic origin, e.g., in the Ruhr Region (Germany) - where long term mining activity causes numerous (1000/year) earthquakes of small magnitudes [49], which is noted by the station EUSK (Figure 6). The Balkan and Turkey area is the only region where $\mathrm{X}$ movements have an opposite direction.

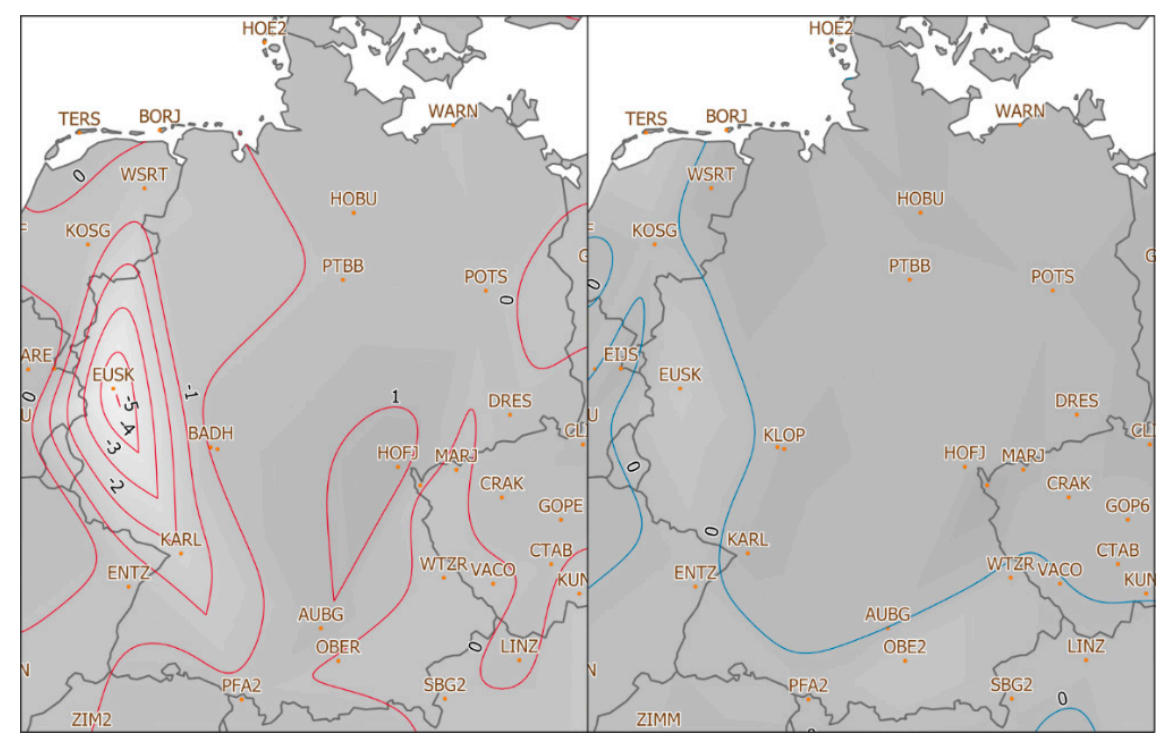

Figure 6. Velocities (mm/year) in ETRF2014 ((left) X component; and (right) Y component) in Germany: In the Ruhr Region (EUSK station), mining activities were performed for many years, and their influence is still noticeable (own study based on [41]).

In the analysis, we focus on the territory of Poland. It is located in the centre of Europe and it does not have any significant anomalous sub-areas. The impact of mining is significantly lower than in other areas, such as the Ruhr Region. Only the EPN station (KATO) in this area has an X velocity value of $1.6 \mathrm{~mm} /$ year (ETRF2014), whereas the rest of the stations do not exceed $1 \mathrm{~mm} /$ year. Figure 7 gives the EPN stations' location and Table 1 shows velocities in this area.

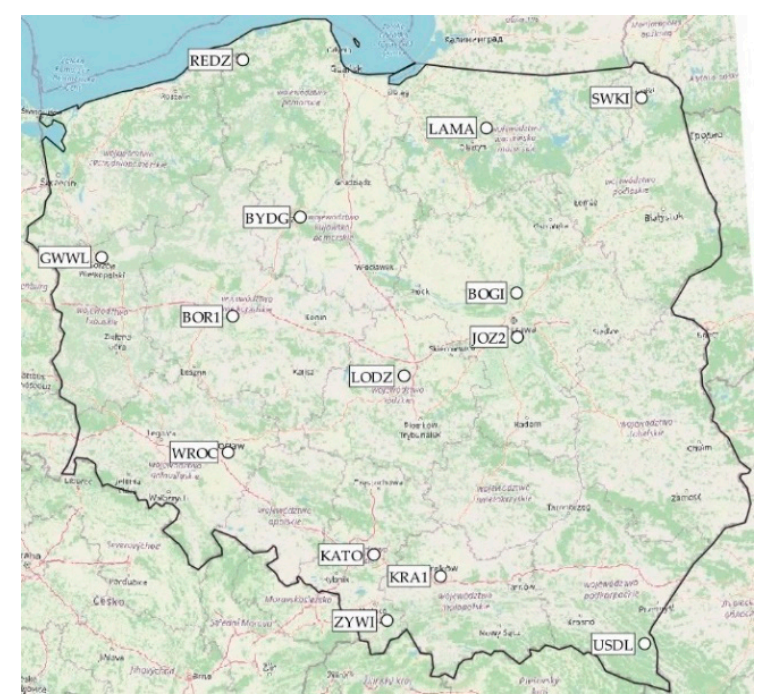

Figure 7. Distribution of the EPN stations at the Poland territory (map background source [50]). 
Poland has annually a seismic activity of about 150 low-magnitude earthquakes [51], compared to about 1000 in the Ruhr Region [49]. Thus, the impact of plate movement on cadastral data may be observed with an insignificant influence of local anomalies.

Table 1. EPN stations' location and velocities located within $49-55^{\circ} \mathrm{N}$ and $15-24^{\circ}$ E.

\begin{tabular}{ccc}
\hline Station & $\mathbf{V}_{\mathbf{x}}(\mathbf{m m} /$ year $)$ & $\mathbf{V}_{\mathbf{y}}(\mathbf{m m} /$ year $)$ \\
\hline BISK & 0.1 & -0.2 \\
BOGI & 0.1 & -0.3 \\
BOGO & -0.1 & -0.6 \\
BOR1 & -0.1 & -0.3 \\
BYDG & 0.0 & -0.4 \\
CFRM & 0.2 & -0.1 \\
CLIB & 0.7 & -0.4 \\
CPAR & 0.2 & -0.3 \\
GWWL & -0.5 & -0.5 \\
JOZ2 & 0.0 & -0.3 \\
JOZE & 0.0 & -0.3 \\
KATO & 1.6 & 0.7 \\
KRA1 & 0.2 & -0.2 \\
KUNZ & -0.7 & 0.0 \\
LAMA & 0.0 & -0.4 \\
LODZ & -0.4 & -0.2 \\
REDZ & 0.5 & -0.1 \\
SWKI & -0.2 & -0.9 \\
TUBO & 0.0 & -0.1 \\
USDL & -0.3 & -0.4 \\
WROC & 0.1 & -0.5 \\
ZYWI & -0.3 & -0.4 \\
\hline
\end{tabular}

The authors determined the maximum displacements in the $X$ and $Y$ directions that occurred in Poland in the past 10, 25 and 50 years (Table 2). These values were calculated from the mean velocities for each coordinate direction of the points located within Poland's territory, based on approximation of the velocities map, as shown in Figure 8.

Table 2. Long-term velocities for three different periods (10, 25 and 50 years).

\begin{tabular}{ccccc}
\hline Reference Frame & Velocity Direction & 10 Years $(\mathbf{m})$ & 25 Years $(\mathbf{m})$ & 50 Years $(\mathbf{m})$ \\
\hline \multirow{2}{*}{ IGS14 } & X & 0.19 & 0.48 & 0.95 \\
& Y & 0.17 & 0.41 & 0.82 \\
\multirow{2}{*}{ ETRF2014 } & XY & 0.25 & 0.63 & 1.25 \\
& X & 0.05 & 0.13 & 0.25 \\
& Y & 0.05 & 0.13 & 0.25 \\
& XY & 0.07 & 0.18 & 0.35 \\
\hline
\end{tabular}

These analyses show a few decimetres in the case of the global (IGS14) reference frame for a 10-25-year period, and close to $1 \mathrm{~m}$ for 50 years. In the case of the local European reference frame (ETRF2014), these values are 3-4 times smaller, and it was between 7 and $35 \mathrm{~cm}$ for the cumulative $X Y$ vector for the 10- and 50-year periods, respectively. 

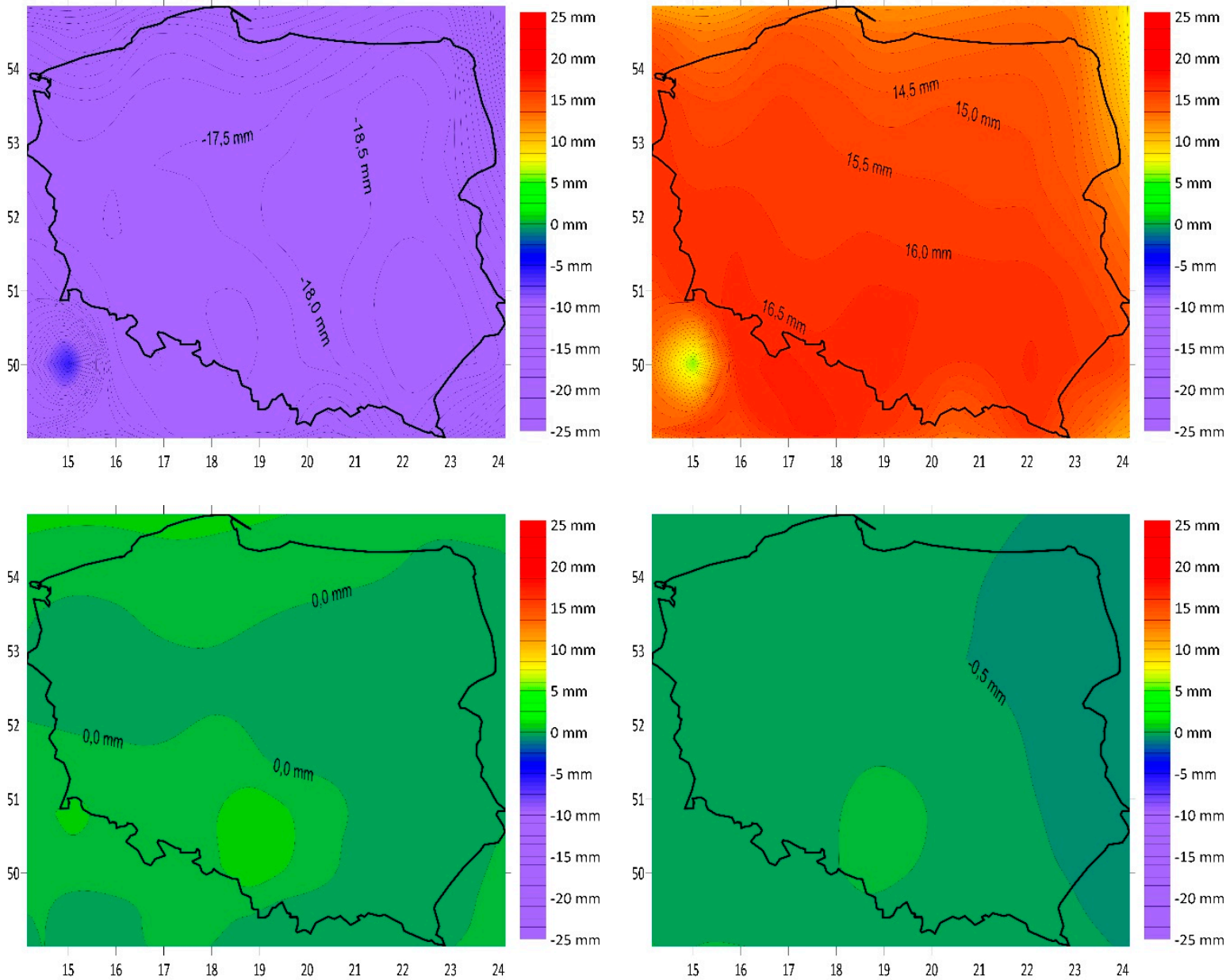

Figure 8. The plate movements for the area of Poland: (top) IGS2014 X (left) and Y (right) components; and (bottom) ETRF2014 X (left) and Y (right) components (own study, based on [41]).

\section{Discussion and Conclusions}

Tectonic plate movements are noticeable, primarily in the global reference frames (ITRF and IGS realisations). Studies have shown a clear 2D northeast direction movement with a mean 22-25 mm/year amplitude for the centre of Europe in the global IGS14. In this context, shifts towards the northeast of $25 \mathrm{~mm} /$ year can be observed in Poland's territory. The use of the ETRF frame reduces the shifts usually below $1 \mathrm{~mm} /$ year. For the needs of the real estate cadastre in Poland, information about parcels' boundary points must be obtained with an accuracy of better than $0.30 \mathrm{~m}$. This accuracy includes, among others, geodetic network errors and measurement errors. Within 25 years, the border mark may be shifted by $0.13 \mathrm{~m}$ (ETRF2014) due to the tectonic plate movement. Considering relative shift of points on the same tectonic plate, this accuracy is negligible noting the required accuracy for border points. Periodic verifications of cadastre data in Poland must be carried out at least once every 15 years (due to [52]), with the data stored in the cadastre regularly updated. In the case of such relatively frequent verification and possible modernisation of data, the potential impact of tectonic plate movement is expected to be negligible. The measurement methods used to determine the location of the boundary points utilise the control points network that move in the same way. Therefore, using traditional measuring methods, it is not possible to determine the offset resulting from the global and local crustal deformations in the absolute sense. It can be concluded that, for areas with low tectonic activity, the impact of such deformations on data disclosure in the real estate cadastre is negligible. Moreover, the movement of the plates has no effect on the surface area of the registration plots presented in the land and building database. 
Concluding, this research clearly showed that the tectonic plate movement has marginal impact to the real estate cadastre in a tectonically stable regions, such as Poland. However, even this small and insignificant impact on the changes of points in some areas is still noticeable. This boils down to the conclusion that, in other, more active regions, these changes may already make a difference. The areas located in the vicinity of transformational faults (horizontal) deserve special attention, e.g., the San Andreas Fault in California, USA or the Alpine Fault on New Zealand's South Island, where the rates of slippage average about 33-37 [53] and $40 \mathrm{~mm}$ /year [54], respectively). This clearly shows the need for this kind of research at different spots of the Earth. At these locations, the automation of the survey system would see the digital capture of land parcel dimensions [55], but to this end we need more research from various points of the Earth. Through connection to the geodetic network, geodetic coordinates would be assigned to parcel boundary points resulting in a coordinate cadastre. As the geodetic network moves, reflecting ground movements, adjustment for this effect could be applied to boundary points forming a dynamic coordinate cadastre. In this manner, coordinates of boundary points would encapsulate available evidence of their true ground positions [55]. Such a research can be a good benchmark. Since land administration is an important tool for delivering sustainable development [6], the cadastre has extended purposes. The cadastres provide the authoritative description of how people relate to specific land and property, and they provide basic and authoritative spatial information in digital land information systems.

Author Contributions: K.M. 30\%, A.P.-S. 25\%, A.E.-M. 15\%, L.B. 20\%, M.A. 10\%. Conceptualisation, K.M., A.P.-S., A.E.-M., L.B. and M.A.; methodology, K.M., A.P.-S., A.E.-M., L.B. and M.A.; software, K.M., A.P.-S., A.E.-M., L.B. and M.A; validation, K.M., A.P.-S., A.E.-M., L.B. and M.A.; formal analysis, K.M., A.P.-S., A.E.-M., L.B. and M.A.; investigation, K.M., A.P.-S., A.E.-M., L.B. and M.A.; resources, K.M., A.P.-S., A.E.-M., L.B. and M.A.; data curation, K.M., A.P.-S., A.E.-M., L.B. and M.A.; writingoriginal draft preparation, K.M., A.P.-S., A.E.-M., L.B. and M.A.; writing-review and editing, K.M., A.P.-S., A.E.-M., L.B. and M.A.; visualisation, K.M., A.P.-S., A.E.-M., L.B. and M.A.; supervision, K.M., A.P.-S., A.E.-M., L.B. and M.A.; project administration, K.M., A.P.-S., A.E.-M., L.B. and M.A.; and funding acquisition, K.M., A.P.-S., A.E.-M., L.B. and M.A. All authors have read and agreed to the published version of the manuscript.

Funding: This paper was supported by statutory research of: AGH No. 16.16.150.545 and LUT No. FN12/ILT/2020.

Institutional Review Board Statement: Not applicable.

Informed Consent Statement: Not applicable.

Data Availability Statement: Not applicable.

Conflicts of Interest: The authors declare no conflict of interest.

\section{References}

1. Williamson, I.; Enemark, S.; Wallace, J.; Rajabifard, A. Land Administration for Sustainable Development; ESRI Press Academic: Redlands, CA, USA, 2010; ISBN 9781589480414.

2. Navratil, G.; Feucht, R. An example for a comprehensive quality description the area in the Austrian cadastre. In Spatial Data Quality; CRC Press: Boca Raton, FA, USA, 2009; pp. 197-209.

3. Hanus, P.; Jasińska, E.; Preweda, E. Analysis of the accuracy of determining the coordinates property borders. In Proceedings of the 9th International Conference "Environmental Engineering 2014"; Vilnius Gediminas Technical University Press “Technika" 2014: Vilnius, Lithuania, 2014.

4. Hanus, P.; Benduch, P.; Pęska-Siwik, A.; Szewczyk, R. Three-stage assessment of parcel area quality. Area 2020, 1-14. [CrossRef]

5. Benduch, P. The Assessment of the influence of average errors of parcels' surface areas on the final result of land properties' valuation process. Geomat. Environ. Eng. 2016, 10, 27-38. [CrossRef]

6. Williamson, I.P. Land administration "best practice" providing the infrastructure for land policy implementation. Land Use Policy 2001, 18, 297-307. [CrossRef]

7. Shah, M.; Jin, S. Pre-seismic ionospheric anomalies of the $2013 \mathrm{Mw}=7.7$ Pakistan earthquake from GPS and COSMIC observations. Geod. Geodyn. 2018, 9, 378-387. [CrossRef]

8. Kozioł, K.; Maciuk, K. New heights of the highest peaks of Polish mountain ranges. Remote Sens. 2020, 12, 1446. [CrossRef] 
9. Hanus, P.; Pęska-Siwik, A.; Benduch, P.; Szewczyk, R. Comprehensive assessment of the quality of spatial data in records of parcel boundaries. Meas. J. Int. Meas. Confed. 2020, 158. [CrossRef]

10. Craig, B.A.; Wahl, J.L. Cadastral survey accuracy, standards. Surv. L. Inf. Sci. 2003, 63, 87-106.

11. van der Molen, P.; Lemmen, C.; Jan Wakker, W.; Lemmen, C. Land Registration and Cadastre in the Netherlands, and The Role of Cadastral Boundaries: The Application of GPS Technology in the Survey of Cadastral Boundaries. J. Geosp. Eng. 2003, 5, 3-10.

12. Van Oosterom, P.J.M.; Lemmen, C.H.J.; Uitermark, H.T.; Boekelo, G.; Verkuijl, G. Land administration standardization with focus on surveying and spatial representations. Proc. ACMS Annu. Conf. Surv. Summit 2011, 28. Available online: https: / / repository.tudelft.nl/islandora/object/uuid:904b4af6-f67e-4abc-80d5-bd649a7134bb/datastream/OBJ/download (accessed on 30 July 2020).

13. Benduch, P.; Peska, A. Comparison of the Methods of Capturing Data Concerning Parcel Boundaries in Aspects of their Accuracy and Reliability. In Proceedings of the International Geographic Information Systems Conference and Exhibition "GIS ODYSSEY 2016", Perugia, Italy, 5-9 September 2016; pp. 25-34.

14. Mallard, C.; Coltice, N.; Seton, M.; Müller, R.D.; Tackley, P.J. Subduction controls the distribution and fragmentation of Earth's tectonic plates. Nature 2016, 535, 140-143. [CrossRef]

15. Spence, W. Slab pull and the seismotectonics of subducting lithosphere. Rev. Geophys. 1987, 25, 55. [CrossRef]

16. Conrad, C.P.; Lithgow-Bertelloni, C. How mantle slabs drive plate tectonics. Science 2002, 298, 207-209. [CrossRef] [PubMed]

17. Segev, A. Flood basalts, continental breakup and the dispersal of Gondwana: Evidence for periodic migration of upwelling mantle flows (plumes). Stephan Mueller Spec. Publ. Ser. 2002, 2, 171-191. [CrossRef]

18. Guzy, A.; Malinowska, A.A. State of the art and recent advancements in the modelling of land subsidence induced by groundwater withdrawal. Water 2020, 12, 51. [CrossRef]

19. Ostřihanský, L. Causes of earthquakes and lithospheric plates movement. Solid Earth Discuss. 2012, 4, 1411-1483. [CrossRef]

20. Nordman, M.; Peltola, A.; Bilker-Koivula, M.; Lahtinen, S. Past and Future Sea Level Changes and Land Uplift in the Baltic Sea Seen by Geodetic Observations. In International Association of Geodesy Symposia; Springer: Berlin, Heidelberg, 2020.

21. Madsen, K.S.; Høyer, J.L.; Suursaar, Ü.; She, J.; Knudsen, P. Sea level trends and variability of the Baltic Sea from 2D statistical reconstruction and altimetry. Front. Earth Sci. 2019, 7, 1-12. [CrossRef]

22. Łyszkowicz, A.; Bernatowicz, A. Geocentric Baltic Sea level changes along the southern coastline. Adv. Sp. Res. 2019, 64, 1807-1815. [CrossRef]

23. E.U. Copernicus Marine Service Information Time Series of Mean Sea Level Trends over Global Ocean. Available online: https:// marine.copernicus.eu/access-data/ocean-monitoring-indicators/time-series-mean-sea-level-trends-over-global-ocean (accessed on 30 July 2020).

24. Boucher, C. Terrestrial Coordinate Systems and Frames. In The Encyclopedia of Astronomy and Astrophysics; IOP Publishing Ltd.: Bristol, UK, 2001.

25. Mueller, I.I. Conventional Terrestrial Reference Frames. J. Geod. 2011, 21, 163-169.

26. IUGG. International Union of Geodesy and Geophysics (IUGG) Resolution Number 2 of Perugia; Bureau International des Poids et Mesures Sevres: Breteuil, France, 2007.

27. Petit, G.; Luzum, B. IERS Conventions (IERS Technical Note No. 36); Bureau International des Poids et Mesures Sevres: Breteuil, France, 2010; p. 179.

28. Altamimi, Z.; Collilieux, X.; Métivier, L. ITRF2008: An improved solution of the international terrestrial reference frame. J. Geod. 2011, 85, 457-473. [CrossRef]

29. Altamimi, Z.; Rebischung, P.; Métivier, L.; Collilieux, X. ITRF2014: A new release of the International Terrestrial Reference Frame modeling nonlinear station motions. J. Geophys. Res. Solid Earth 2016, 121, 6109-6131. [CrossRef]

30. Kouba, J.; Popelar, J. Modern geodetic reference frames for precise satellite positioning and navigation. In International Symposium on Kinematic Systems in Geodesy, Geomatics \& Navigation (KIS 94); Department of Geomatics Engineering, University of Calgary: Calgary, AB, Canada, 1994; pp. 79-85.

31. Feissel-Vernier, M.; de Viron, O.; Le Bail, K. Stability of VLBI, SLR, DORIS, and GPS positioning. Earth Planets Space 2007, 59, 475-497. [CrossRef]

32. Altamimi, Z.; Rebischung, P.; Métivier, L.; Collilieux, X. The International Terrestrial Reference Frame: Lessons from ITRF2014. Rend. Lincei. Sci. Fis. Nat. 2018, 29, 23-28. [CrossRef]

33. Cai, J. The systematic analysis of the transformation between the German geodetic reference system (DHDN, DHHN) and the ETRF system (DREF91). Earth Planets Space 2000, 52, 947-952. [CrossRef]

34. Boucher, C.; Altamimi, Z. Memo: Specifications for Refer-Ence Frame Fixing in the Analysis of a EUREF GPS Campaign 2011, 9. Available online: http:/ / users.auth.gr/kvek/20070327-MEMO-ver6.pdf (accessed on 30 July 2020).

35. Zhu, W.; Song, S.; He, L. Recommendations for construction of a nonlinear international Terrestrial Reference Frame. Sci. China Phys. Mech. Astron. 2011, 54, 164-171. [CrossRef]

36. Rabah, M.; Elmewafey, M.; Farahan, M.H. Datum maintenance of the main Egyptian geodetic control networks by utilizing Precise Point Positioning "PPP" technique. NRIAG J. Astron. Geophys. 2016, 5, 96-105. [CrossRef]

37. Ze, Z.; Guojie, M.; Xiaoning, S.; Jicang, W.; Xiaojing, L.J. Global crustal movement and tectonic plate boundary deformation constrained by the ITRF2008. Geod. Geodyn. 2015, 3, 40-45. [CrossRef] 
38. Royal Observatory of Belgium Map of EPN Station Positions \& Velocities. Available online: http://www.epncb.oma.be/ _productsservices/coordinates/posvel_map.php (accessed on 30 July 2020).

39. Altamimi, Z. EUREF Technical Note 1: Relationship and Transformation between the International and the European Terrestrial Reference Systems. Available online: http:/ / etrs89.ensg.ign.fr/pub/EUREF-TN-1.pdf (accessed on 30 July 2020).

40. Bosy, J. Global, regional and national geodetic reference frames for geodesy and geodynamics. Pure Appl. Geophys. 2014, 171, 783-808. [CrossRef]

41. Royal Observatory of Belgium Positions \& Velocities. Available online: http://www.epncb.oma.be/_productsservices/ coordinates / (accessed on 6 August 2020).

42. Henriksen, $\mathrm{H}$. The role of some regional factors in the assessment of well yields from hard-rock aquifers of Fennoscandia. Hydrogeol. J. 2003, 11, 628-645. [CrossRef]

43. Bogdanov, V.I. Generalization of hypothesis on nature of the Fennoscandia postglacial uplift phenomenon. Dokl. Earth Sci. 2010, 433, 911-914. [CrossRef]

44. Groves, P.D. Principles of GNSS, inertial, and multisensor integrated navigation systems. In Artech House, 2nd ed.; IEEE: New York, NY, USA, 2013; p. 776.

45. Li, X.; Ge, M.; Dai, X.; Ren, X.; Fritsche, M.; Wickert, J.; Schuh, H. Accuracy and reliability of multi-GNSS real-time precise positioning: GPS, GLONASS, BeiDou, and Galileo. J. Geod. 2015, 89, 607-635. [CrossRef]

46. Sztwiertnia, D.; Ochałek, A.; Tama, A.; Lewińska, P. HBIM (Heritage Building Information Model) of the Wang Stave church in Karpacz-Case study. Int. J. Archit. Herit. 2019, 1-15. [CrossRef]

47. Kampczyk, A. Magnetic-measuring square in the measurement of the circular curve of rail transport tracks. Sensors 2020, 20, 560. [CrossRef] [PubMed]

48. Kampczyk, A. Measurement of the geometric center of a turnout for the safety of railway infrastructure using mms and total station. Sensors 2020, 20, 4467. [CrossRef] [PubMed]

49. Bischoff, M.; Cete, A.; Fritschen, R.; Meier, T. Coal mining induced seismicity in the Ruhr Area, Germany. Pure Appl. Geophys. 2010, 167, 63-75. [CrossRef]

50. OpenStreetMap Contributors OpenStreetMap. Available online: https:/ / www.openstreetmap.org (accessed on 25 January 2021).

51. Polish Geological Institute National Research Institute Dane Dotyczace Aktywności Sejsmicznej w Polsce w Latach 2013-2016. 2017. Available online: https:/ / www.pgi.gov.pl/index.php?option=com_attachments\&task=download\&id=19542 (accessed on 25 January 2021).

52. Minister of Regional Development and Construction Regulation of the Minister of Regional Development and Construction of 29 March 2001 on the Register of Land and Buildings 2001, 70. Available online: http:/ /isap.sejm.gov.pl/isap.nsf/download.xsp/ WDU20010380454/O/D20010454.pdf (accessed on 25 January 2021).

53. Wallace, R.E. The San Andreas fault system. US Geol. Surv. Prof. Pap. 1990, 1515. Available online: https://pubs.usgs.gov/pp/19 90/1515/pp1515.pdf (accessed on 25 January 2021).

54. Thornton, J. Field Guide to New Zealand Geology: An Introduction to Rocks, Minerals and Fossils; Reed Publishing: Auckland, New Zealand, 1985; ISBN 0790004054.

55. Blick, G.; Grant, D. Possibility of a dynamic cadastre for a dynamic nation. In Advances in Positioning and Reference Frames International Association of Geodesy Symposia; Springer: Berlin/Heidelberg, Germany, 1998; pp. 107-113. 